\title{
Experimental Investigation on Combustion Characteristics of Refine Corn Oil with Areca Catechu Extract as Additive
}

\author{
Wardoyo $^{a}$, Agung S.Widodo ${ }^{b}$, Widya Wijayanti ${ }^{b}$, I. N. G. Wardana ${ }^{b}$ \\ ${ }^{a}$ Department of Mechanical Engineering, State University of Jakarta, Jakarta, Indonesia \\ bDepartment of Mechanical Engineering, Brawijaya University, Malang Indonesia \\ e-mail: wardoyo@unj.ac.id
}

\begin{abstract}
The need for vegetable oils as alternative energy reserves increases with the depletion of fossil energy sources. Vegetable oil is the strongest candidate to replace the fossil energy. However, the use of vegetable oil directly as fuel is limited by high viscosity. Viscosity like this results in non-ideal atomization, challenging to evaporate, and cannot burn completely. Among the methods that have been studied by previous researchers and which have proven to be effective, cheaper, and can reduce the viscosity of vegetable oils better is the mixing method. In this study, corn oil was mixed with areca extract as an additive. Areca extract contains polyphenols which are polar types of epicatechin. Epicatechin has three aromatic rings and several hydroxyl groups. Delocalisation of electrons in aromatic rings can produce London forces on vegetable oil molecules, thereby increasing the reactivity of burning vegetable oil droplets. The burning characteristics of corn vegetable oil affected by areca extract have been studied experimentally at room temperature and atmospheric pressure. The results showed that the rate and temperature of combustion increased, as well as the presence of micro explosions. The London force that appears causes the bonds in the triglyceride molecules to weaken so that the combustion becomes reactive, the rate of heat transfer in the droplets gets better, facilitates the appearance of micro explosions and increases the combustion temperature. Vegetable oil from corn has been studied experimentally at atmospheric pressure and room temperature. The results show an increase in the rate of combustion, an increase in combustion temperature, and the presence of micro explosions. London force that appears causes the bonds in the triglyceride molecules to weaken so that combustion becomes more reactive, the rate of heat transfer in the droplet gets better, facilitates the appearance of micro explosions and raises the combustion temperature.
\end{abstract}

Keywords: corn oil; epicatechin; London force; combustion; micro explosion

\section{INTRODUCTION}

Energy has become a primary need for human life in meeting the needs of life and developing its economy. In the last decade, energy use has increased rapidly as a result of the rapidly growing transportation and manufacturing business. On the other hand, conventional energy reserves in nature are running low, and this leads to the global energy crisis [1]. Therefore, new sources of energy are needed to replace the fossil energy. Biodiesel as a fuel that has biodegradable properties, obtained from renewable sources, lower pollution from petroleum is the main candidate to answer the above problem [2].

Biodiesel is a renewable fuel made from vegetable oils or animal fats consisting of triglycerides, after going through a process of separation into fat esters and glycerol. It is not dangerous for the environment because of its low toxicity and high biodegradation. 
Biodiesel has a value of viscosity, specific gravity, and heating value that is comparable to diesel oil [3] but biodiesel has a higher cetane number than diesel oil, which will reduce flame delays when burning in high-pressure chambers. However, to convert plant oils into biodiesel requires expensive costs that are not comparable to the price of diesel fuel. Therefore it is necessary to improve the properties of vegetable oil so that it can be used directly without changing it first into biodiesel.

The density value of vegetable oil is $917 \mathrm{~kg} / \mathrm{m}^{3}$, kinematic viscosity $35.52 \mathrm{cst}$, and flash point $243^{\circ} \mathrm{C}$. While the density of diesel oil is $818 \mathrm{~kg} / \mathrm{m}^{3}$, kinematic viscosity is 5.8 cst, and the flashpoint is $150^{\circ} \mathrm{C}$. Its high viscosity directly limits the use of vegetable oil as fuel, because it produces no ideal atomization, is difficult to evaporate, combustion cannot be perfect, and shortens the life of the fuel filter [4]. Also, high-viscosity fuels can accelerate the wear of fuel system components in diesel engines [5].

Vegetable oil is composed of glycerol compounds and fatty acid chains. Combined glycerol and fatty acid chains in vegetable oils are mostly in the form of triglyceride molecules and a small portion of diglycerides and monoglycerides. Vegetable oil is converted into biodiesel by separating glycerol from fatty acids through degumming, esterification, trans-esterification, hydrogenation, and catalytic cracking processes [6]. All of these processes require huge costs to convert vegetable oil into biodiesel, so the price of biodiesel is $10 \%$ to $50 \%$ more expensive than diesel fuel [7].

Many studies have proposed and studied alternative solutions to reduce the viscosity of vegetable oils so that the cost of biodiesel production becomes cheaper, such as with micro-emulsions, preheating, and mixing methods [8][9][10]. The method that has been studied and is believed to be effective, cheaper, and quick to change the physical properties of vegetable oils to be more dilute is the mixing method. Over the past decade, researchers mixing vegetable-vegetable oils, vegetable-alcohol oils, and vegetable-alcohol-diesel have shown that the viscosity produced can decrease in proportion to diesel. Previous researchers have widely studied vegetable oil mixtures with different percentage of mixtures and show almost the same results [11]. In a mixture of vegetable oil and diesel oil with a composition of $20 \%$ vegetable oil and $80 \%$ diesel oil can be applied directly to diesel engines without modification. However, this mixture still uses fossil fuels as the central element in the mixture [12].

Another effort made by previous researchers to find a substitute for diesel fuel is to use a vegetable-alcohol oil mixture. Usually, they use a type of alcohol ethanol and methanol. Because the level of solubility of vegetable oils in this type of alcohol is low, surfactants are used as additives to improve the mixing ability and stability of the mixture [13]. Other researchers used pentanol and butanol type alcohols, which have physical properties that are closer to diesel oil and have better stability and solubility compared to ethanol and methanol alcohols. Then, vegetable oil can be mixed perfectly with butanol and pentanol without surfactants. Butanol and pentanol are runny so they can reduce the high viscosity effect of vegetable oils in the mixture. Butanol and pentanol have high oxygen content, and these characteristics can reduce particulate emissions from this fuel mixture [14].

Wardana (2010) [15] examined the characteristics of castor oil combustion by adjusting the initial combustion temperature variation. The results showed that high oil temperatures reduce its viscosity, and increase the likelihood of microexplosion. In vegetable oils, micro explosions can occur because fatty acids have different boiling points with glycerol.

One of the combustion characteristics that can be used as a parameter of combustion efficiency measurement is the micro-explosion. Its happens when there is a difference in the boiling point of the composition of the fuel compiler. Micro-explosion causes the formation of tiny fuel droplets, making fuel combustion easier and more evenly distributed at high temperatures [16].

Hendry et al. (2010) [17], improved the properties of vegetable oils by adding rhodium sulfate $\left(\mathrm{Rh}^{+}\right)$as a catalyst in castor oil, coconut oil, and sunflower oil. The results show that Rh3 + can change the geometry of fatty acids and help in the process of thermal decomposition and cranking so that the embodiment and strength of micro explosions increase. 
In this study, it is using areca extract as an additive to improve the properties of vegetable oils. Betel nut contains polyphenols, polar type of epicatechin. Epicatechin forms hydrogen bonds on the polar triglyceride head of corn oil. The aromatic ring on epicatechin has electron delocalization which can generate London force on triglycerides, causing stretching of the vegetable oil molecules (Figure 1). As a result, vegetable oil becomes more reactive when burned and triggers the formation of micro-explosion. This test is carried out by observing the burning characteristics of corn oil droplets and recording the rate of change in the center temperature of the droplet when it burns.

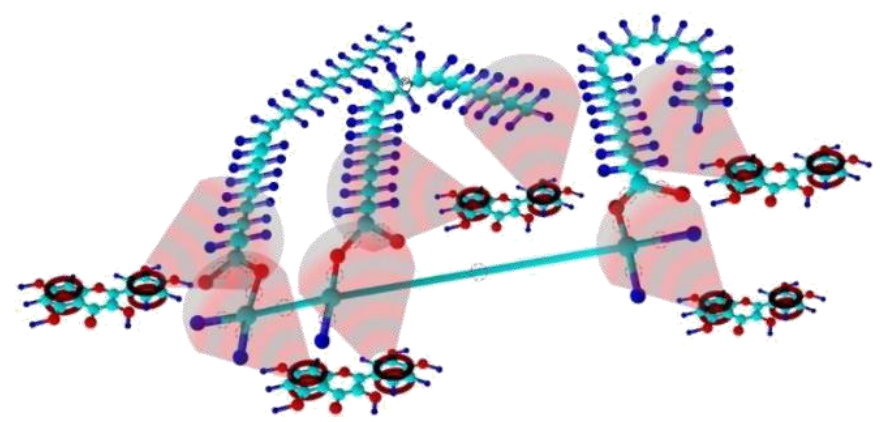

Figure 1. The process of delocalized electrons in the aromatic ring of Epicathecin generates London force on triglycerides

\section{Material AND Methods}

Mature areca seeds are picked from the areca nut plantation in the east of Tanjung Jabung Regency, east of Jambi province, Indonesia. Areca nuts are dried, made into flour, and cold extracted with Analytical methanol solvent from the Indonesian smart lab. Palm oil and corn oil are purchased from local minimarkets while coconut oil is produced by the heating method.

The measurement technique used in this study follows the previous research procedures in reference [15]. One drop of natural fuel suspended at a thermocouple junction made of $\mathrm{Pt} / \mathrm{Rh} 13 \%$ ( $0.1 \mathrm{~mm}$ diameter). Corn droplet oil is regulated to have a diameter of about $0.7-1.2 \mathrm{~mm}$. Droplets were burned using a Ni-Cr coil heater $(0.9 \mathrm{~mm}$ diameter, $90 \mathrm{~mm}$ long). Wire type resistance is $1.04 \Omega$. This electric heater connected to a $12-\mathrm{V}$ DC power supply with an electric current of $5 \mathrm{~A}$. Droplets of corn oil is made using microsyringes, and combustion is carried out under environmental conditions of atmospheric pressure and room temperature. Observation of the characteristics of droplets and the shape of the corn oil burning fire was carried out using a micro camera. The equipment used in this experiment is as shown in Figure 1.

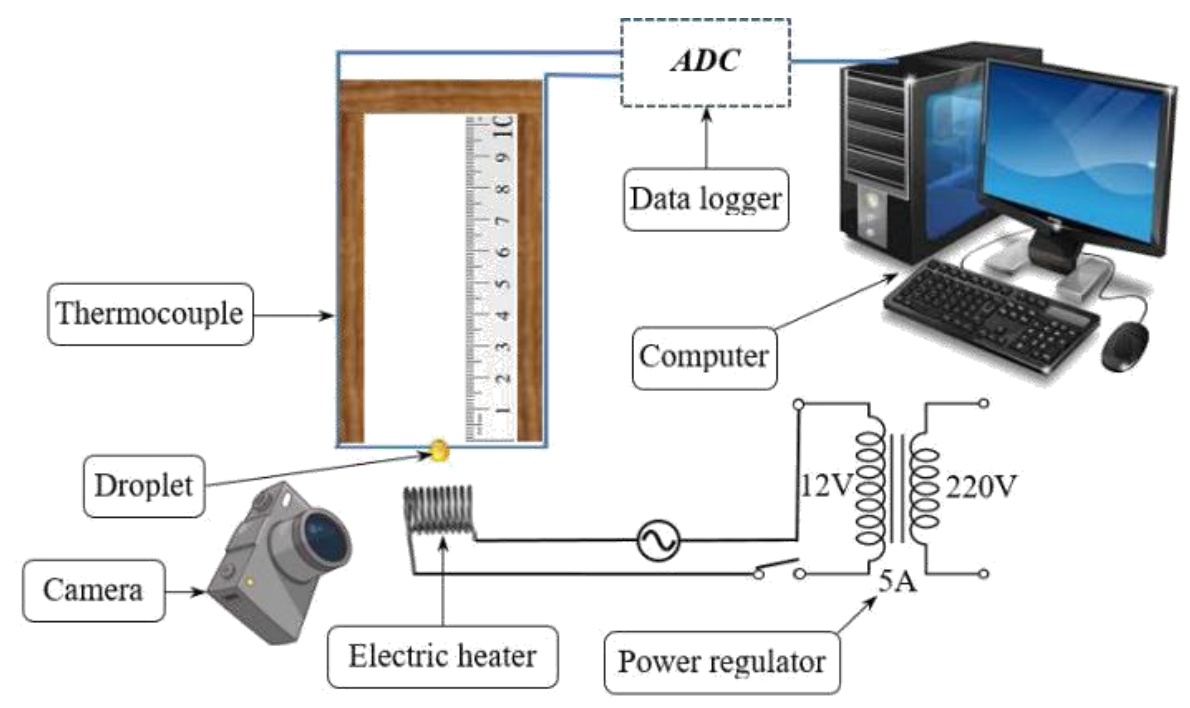

Figure 2. Experimental apparatus 
The measurement technique used in this study follows the previous research procedure given in [15]. One drop of natural fuel suspended at a thermocouple junction made of $\mathrm{Pt} / \mathrm{Rh} 13 \%$ ( $0.1 \mathrm{~mm}$ diameter). Corn drip oil is regulated to have a diameter of about $0.7-1.2 \mathrm{~mm}$. Droplets were burned using a Ni-Cr coil heater $(0.9 \mathrm{~mm}$ diameter, 90 $\mathrm{mm}$ long). Wire type resistance is $1.04 \Omega$. This electric heater connected to a $12-\mathrm{V}$ DC power supply with an electric current of $5 \mathrm{~A}$. Droplets of corn oil is made using microsyringes, and combustion is carried out under environmental conditions of atmospheric pressure and room temperature. Observation of the characteristics of droplets and the shape of the corn oil burning fire was carried out using a micro camera. The equipment used in this experiment is as shown in Figure 2.

\section{RESULTS AND Discussion}

The results of observing the temperature at the center of the corn oil droplet when it is burning are shown in Figure 3. Temperature evolution in the center of corn oil droplets. The temperature increases simultaneously from the start of the combustion heating. With the same heat flux from 0 to 0.5 seconds, the temperature rise in the center of the identical droplet is between one sample and the other. After 0.7 seconds, the temperature in the center of the corn oil droplet with additives rises faster than pure corn oil. It also shows that the oil with the additives can be burnt earlier. Corn oil with additives of $250 \mathrm{ppm}$ and 500 ppm burns faster in quick succession. After that, it decreases in additive content of 750 ppm then $1000 \mathrm{ppm}$. The peak temperature of droplet combustion increases with increasing additive content in corn vegetable oil, starting from 250 ppm, 500 ppm, 750 ppm, and $1000 \mathrm{ppm}$.

At the time of droplet preheating, there are no prominent characteristic differences. At the change in time from 0 to 0.5 seconds, there is an increase in the temperature of the droplet between $28^{\circ} \mathrm{C}-45^{\circ} \mathrm{C}$. In this condition, the additive added has not yet seen its effect.

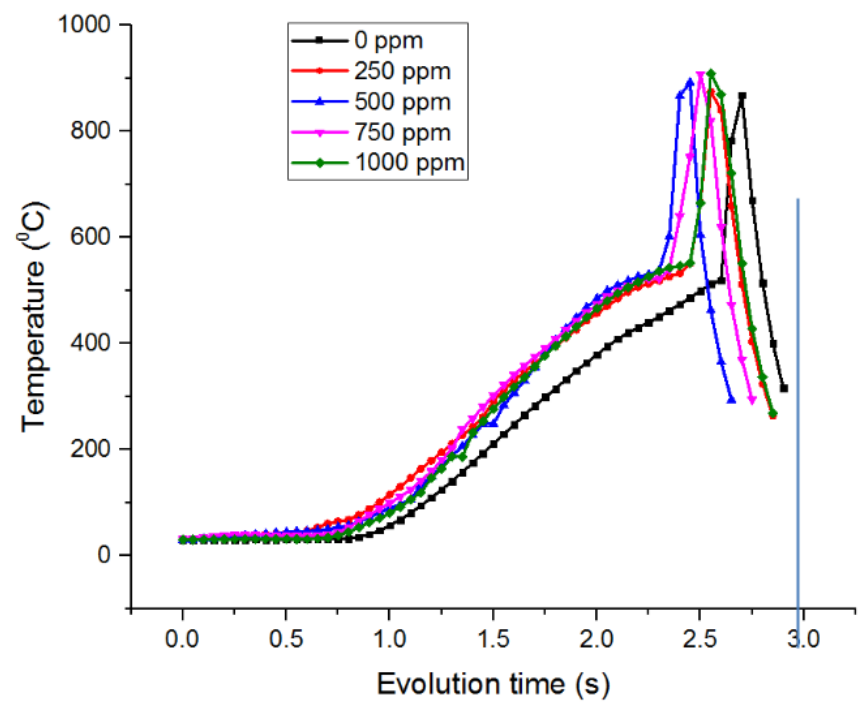

Figure 3. Temperature evolution in the center of corn oil droplets

The second stage of heating is the droplet evaporation process, occurring at 0.5 to 0.7 seconds. Areca nut extract can help absorb heat from the heater and forward it to the center of the droplets for the better. It can be seen in Figure 4. Temperature evolution in the center of corn oil droplets, temperature droplets with additives higher than without additives. It happens because the electron delocalization in epicatechin gives rise to London force in vegetable oils so that the molecular vibration intensity increases and the molecular structure is disrupted and weakened. This phenomenon causes heat absorption from the heating coil to be better than droplets without additives. 


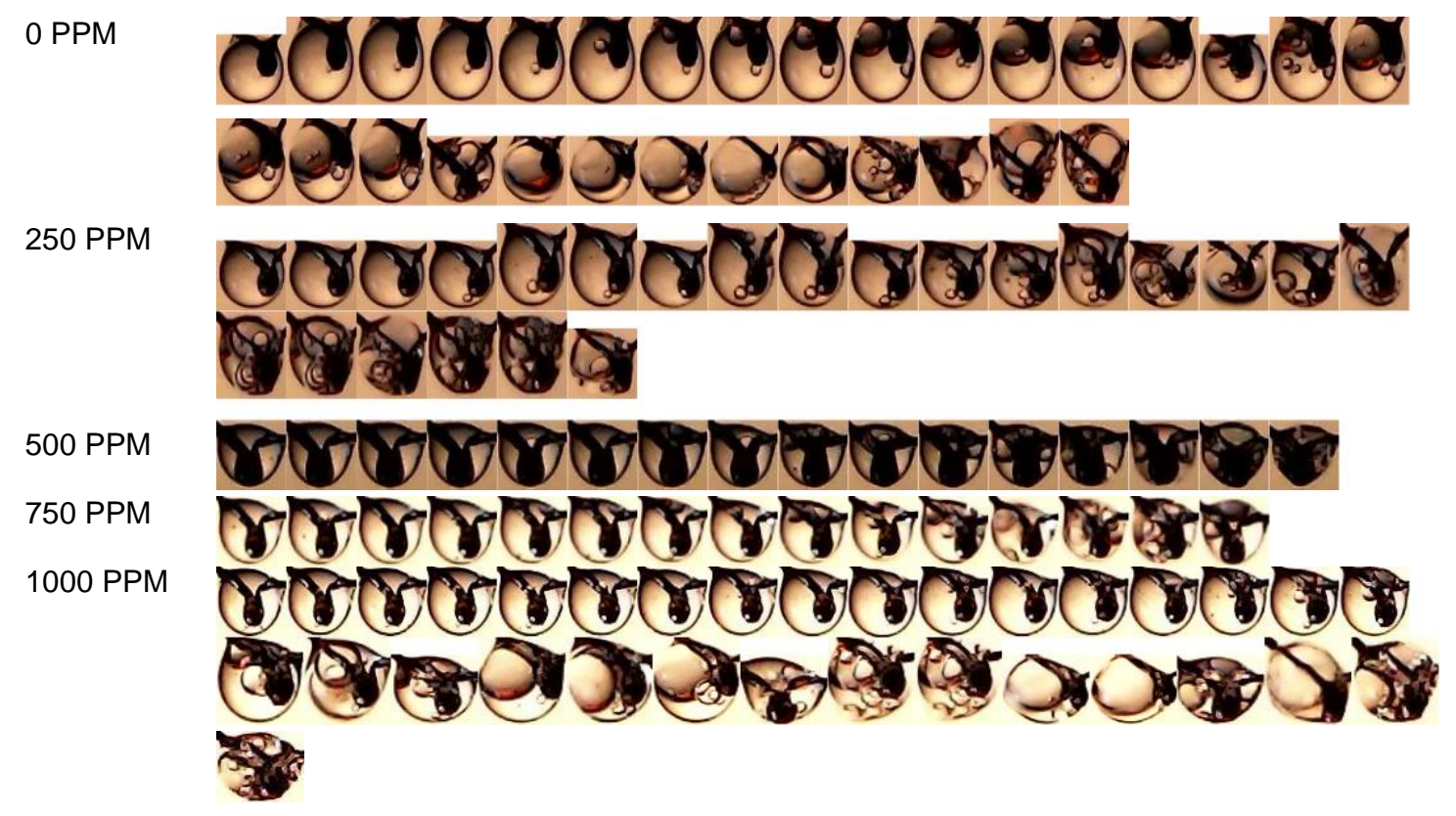

Figure 4. Bubble growth in the droplets of corn oil

The third phase of the combustion process is the burning of corn oil droplets. Corn oil droplets with additives will burn at 2.25 to 2.6 seconds, while pure corn oil droplets will burn at 2.6 to 2.9 seconds. When the vegetable oil molecule has been weakened by the London force, it will be more volatile and more flammable. From the Fig. 3 also shows that the corn oil droplet with additive produces a higher temperature. Its shows that it turns out that additive areca nut extract in addition to increasing heat absorption, accelerates the combustion process can also increase the combustion temperature of the droplet.

Figure 4 shows the growth of air bubbles in the droplet. In pure corn oil droplets $(0$ ppm), air bubbles appear small in size, then enlarge slowly. After the first significant size of air bubbles then massive new air bubbles appear and then the droplet catches on fire. They are starting from the appearance of small bubbles until its burning in around 1 second.

In additive concentrations in low and medium corn oil $(250 \mathrm{ppm}, 500 \mathrm{ppm}$, and 750 $\mathrm{ppm}$ ), growth in size and number of air bubbles in the droplet increased. Both of these additive concentrations have optimum values on the composition of areca extract $500 \mathrm{ppm}$ and $750 \mathrm{ppm}$. At an additive concentration of $1000 \mathrm{ppm}$, it takes almost the same time as the pure corn oil droplet. However, droplets with 1000 ppm additives have more massive growth of bubbles compared to droplets without additives.

The growth of bubbles in the droplet indicates the start of the boiling point of the droplet. The bubble growth rate shows a better distribution of heat in the bubbles. Figure 4 shows that corn oil droplets with additives have more moderate boiling characteristics compared to pure corn oil droplets. It is in line with the graph in Figure 3, the rate of heat absorption of corn oil droplets with additives looks faster when compared to those without additives.

\section{Conclusions}

Cold extraction of Areca nut with methanol produces epicatechin as the main composition. The epicatechin molecule consists of three aromatic rings with several hydroxyl groups. Delocalizations of electron in the aromatic ring will generate London forces in the molecular structure of triglycerides. Corn oil that has been exposed to the London force has weakened triglyceride molecules, which will be more reactive when burned.

\section{ACKNOWLEDGMENTS}

The authors would like to thank the Indonesian Endowment Fund for Education (LPDP) from the Indonesian Ministry of Finance (Grant No. 2016 1141011771) for support for the work reported in this article. 


\section{REFERENCES}

1. M. Al Qubeissi, S. S. Sazhin, and A. E. Elwardany, "Modelling of blended Diesel and biodiesel fuel droplet heating and evaporation," Fuel, 2017; vol. 187:349-355. https://doi.org/10.1016/i.fuel.2016.09.060

2. O. M. Ali, R. Mamat, N. R. Abdullah, and A. Adam, "Analysis of blended fuel properties and engine performance with palm biodiesel e diesel blended fuel," Renew. Energy, 2016; Vol. 86:59-67. https://doi.org/10.1016/i.renene.2015.07.103

3. P. Verma and M. P. Sharma, "Comparative analysis of effect of methanol and ethanol on Karanja biodiesel production and its optimisation," Fuel, 2016; Vol. 180:164-174, 2016. https://doi.org/10.1016/j.fuel.2016.04.035

4. H. K. Imdadul et al., "Higher alcohol-biodiesel-diesel blends: An approach for improving the performance, emission, and combustion of a light-duty diesel engine," Energy Convers. Manag., 2016; Vol. 111:174-185. https://doi.org/10.1016/i.enconman.2015.12.066

5. S. Che, M. Y. Idroas, Y. H. Teoh, and M. F. Hamid, "Optimisation of viscosity and density of re fi ned palm Oil-Melaleuca Cajuputi oil binary blends using mixture design method," Renew. Energy, 2019; Vol. 133:393-400. https://doi.org/10.1016/i.renene.2018.10.017

6. M. Zhang and H. Wu, "Effect of major impurities in crude glycerol on solubility and properties of glycerol / methanol / bio-oil blends," Fuel, 2015; Vol. 159:118-127. https://doi.org/10.1016/i.fuel.2015.06.062

7. D. Y. C. Leung and Y. Guo, "Transesterification of neat and used frying oil: Optimization for biodiesel production," Fuel Processing Technology, 2006; Vol. 87(10):883-890. https://doi.org/10.1016/..fuproc.2006.06.003

8. A. Atmanli, E. Ileri, B. Yuksel, and N. Yilmaz, "Extensive analyses of diesel - vegetable oil - n -butanol ternary blends in a diesel engine," Applied Energy, 2015; Vol. 145:155162. https://doi.org/10.1016/i.apenergy.2015.01.071

9. O. M. I. Nwafor, "Emission characteristics of diesel engine running on vegetable oil with elevated fuel inlet temperature," Biomass and Bioenergy, 2004; Vol. 27(5):507511. https://doi.org/10.1016/i.biombioe.2004.02.004

10. D. H. Qi, C. Bae, Y. M. Feng, C. C. Jia, and Y. Z. Bian, "Combustion and emission characteristics of a direct injection compression ignition engine using rapeseed oil based micro-emulsions," Fuel, 2013; Vol. 107:570- 577. https://doi.org/10.1016/i.fuel.2013.01.046

11. A. K. Agarwal and A. Dhar, "Experimental investigations of performance, emission and combustion characteristics of Karanja oil blends fuelled DICl engine," Renewable Energy, 2013; Vol. 52:283-291. https://doi.org/10.1016/i.renene.2012.10.015

12. P. Singh, S. R. Chauhan, and N. Kumar, "A review on methodology for complete elimination of diesel from $\mathrm{Cl}$ engines using mixed feedstock," Renewable and Sustainable Energy Reviews, 2016; Vol. 57:1110-1125. https://doi.org/10.1016/i.rser.2015.12.090

13. S. Bhimani, J. L. Alvarado, K. Annamalai, and C. Marsh, "Emission characteristics of methanol-in-canola oil emulsions in a combustion chamber," Fuel, 2013; Vol. 113:97106. https://doi.org/10.1016/j.fuel.2013.04.083

14. T. Laza and Á. Bereczky, "Basic fuel properties of rapeseed oil-higher alcohols blends," Fuel, 2011; Vol. 90:803-810. https://doi.org/10.1016/i.fuel.2010.09.015

15. I. N. G. Wardana, "Combustion characteristics of jatropha oil droplet at various oil temperatures," Fuel, 2010; Vol. 89(3):659-664. https://doi.org/10.1016/i.fuel.2009.07.002

16. P. Le Clercq, B. Noll, and M. Aigner, "Modeling Evaporation and Microexplosion of Water-in-Alkane Emulsion Droplets," AIChE Annu. Meet. Conf. Proc., 2006.

17. H. Y. Nanlohy, I. N. G. Wardana, N. Hamidi, L. Yuliati, and T. Ueda, "The effect of $\mathrm{Rh}^{3+}$ catalyst on the combustion characteristics of crude vegetable oil droplets," Fuel, 2018; Vol. 220:220- 232. https://doi.org/10.1016/j.fuel.2018.02.001 